\title{
"A new method of measuring stock market manipulation through structural equation modeling (SEM)"
}

\begin{tabular}{|c|c|}
\hline AUTHORS & $\begin{array}{l}\text { Maruf Rahman Maxim } \\
\text { Abu Sadat Muhammad Ashif }\end{array}$ \\
\hline ARTICLE INFO & $\begin{array}{l}\text { Maruf Rahman Maxim and Abu Sadat Muhammad Ashif (2017). A new method of } \\
\text { measuring stock market manipulation through structural equation modeling } \\
\text { (SEM). Investment Management and Financial Innovations, 14(3), 54-61. } \\
\text { doi:10.21511/imfi.14(3).2017.05 }\end{array}$ \\
\hline DOI & http://dx.doi.org/10.21511/imfi.14(3).2017.05 \\
\hline RELEASED ON & Tuesday, 10 October 2017 \\
\hline RECEIVED ON & Wednesday, 29 March 2017 \\
\hline ACCEPTED ON & Tuesday, 12 September 2017 \\
\hline LICENSE & $\begin{array}{l}(c)) \text { EY-Nc } \\
\text { This work is licensed under a Creative Commons Attribution-NonCommercial } 4.0 \\
\text { International License }\end{array}$ \\
\hline JOURNAL & "Investment Management and Financial Innovations" \\
\hline ISSN PRINT & $1810-4967$ \\
\hline ISSN ONLINE & $1812-9358$ \\
\hline PUBLISHER & LLC "Consulting Publishing Company "Business Perspectives" \\
\hline FOUNDER & LLC "Consulting Publishing Company "Business Perspectives" \\
\hline
\end{tabular}

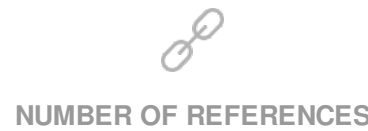

26
NUMBER OF FIGURES

1
ニ:ニ

NUMBER OF TABLES

0

(C) The author(s) 2022. This publication is an open access article. 


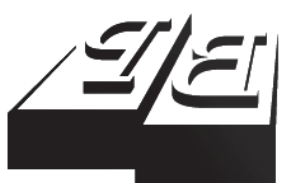

BUSINESS PERSPECTIVES

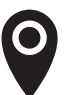

LLC "CPC "Business Perspectives" Hryhorii Skovoroda lane, 10, Sumy, 40022, Ukraine

www.businessperspectives.org

Received on: $29^{\text {th }}$ of March, 2017 Accepted on: $12^{\text {th }}$ of September, 2017

(c) Maruf Rahman Maxim, Abu Sadat Muhammad Ashif, 2017

Maruf Rahman Maxim, Casual Lecturer, Charles Darwin University, Australia.

Abu Sadat Muhammad Ashif, Assistant Professor, East West University, Bangladesh.

\section{(ㄷ)(1) $(8$}

This is an Open Access article, distributed under the terms of the Creative Commons Attribution-NonCommercial 4.0 International license, which permits re-use, distribution, and reproduction, provided the materials aren't used for commercial purposes and the original work is properly cited.

\section{A NEW METHOD OF MEASURING STOCK MARKET MANIPULATION THROUGH STRUCTURAL EQUATION MODELING (SEM)}

\begin{abstract}
This paper proposes a new model of measuring a latent variable, stock market manipulation. The model bears close resemblance with the literature on economic well-being. It interprets the manipulation of a stock as a latent variable, in the form of a multiple indicators and multiple causes (MIMIC) model. This approach exploits systematic relations between various indicators of manipulation and between manipulation and multiple causes, which allows it to identify the determinants of manipulation and an index of manipulation simultaneously. The main reason of stock market manipulation comes from the fact that information availability is not universally equal. The manipulation is thus critically linked to the creation, arrival and dissemination of information or rumors/mis-information. Thus, the immediate impact of manipulation is on the time profile of returns, or excess returns, from an asset and the excess volatility of returns in excess of the volatility explained by the fundamentals. In this basic setup, the model used these two variables as the indicators of stock market manipulation. The main intuition of the MIMIC approach is that some variables, or statistics, related to peace are indicators of manipulation, while others signify effects or outputs of causal factors, or inputs, of manipulation. In other words, distinction can be made between causes of manipulation and indicators of manipulation. The causal factors used in this model are classified into five different domains namely pure economic factors as determinants of manipulation, labor market conditions, international factors, quality of governance factors and systematic risk factors.
\end{abstract}

\section{Keywords market manipulation, market misconduct, structural equation model}

\section{JEL Classification G18, G28, C39}

\section{INTRODUCTION}

The financial world today is far more complex and integrated due to the rapid advancement of technology coupled with trade globalization. The complexity of the market, however, makes it more vulnerable to different forms of market manipulation which subsequently creates inefficiency in the market. The true forces of the market, supply and demand cannot completely regulate the price in an inefficient market which harms the legitimate traders in the long run. It is easy to see why manipulation is detrimental to the market, however, quite difficult to define it in words and therefore challenging to observe and measure.

In loose terms, market manipulation would be any deliberate act that disrupts the true market price of a stock. Any effort to create an artificial or misleading price signal can be labeled as manipulation (Goldwasser, 1999). A very holistic and well recognized classification 
of manipulation was given by Allen and Gale (1992), as they categorized manipulation in three major categories: (i) action-based manipulation, (ii) information-based manipulation and (iii) size-based manipulation. As the name suggests, action-based manipulation would be any action taken by the investor or the management of the firm with the intention to manipulate the price. The firm itself has the influence to sway public perception by taking intentional favorable or unfavorable managerial decisions to artificially alter the price (Chatterjea, Cherian, \& Jarrow, 1993). Trading on any inside information or spreading any rumor to influence the market price and capitalize on that is categorized as information-based manipulation. Manipulative strategies such as 'bear raid' (Vila, 1989), 'pump and dump' (Pickholz \& Pickholz, 2001) etc. can be marked as prime examples of information-based manipulation. Lastly, as Jarrow (1992) pointed out, large traders due to their size advantage have significant influence on the market. Therefore they can artificially distort the market price with their buying power and can calibrate it in their favor. Such manipulative act can be labelled as size-based manipulation. The definition of punishable manipulation however varies from country to country and it is difficult to give a uniform strict definition that is conformed by all judicial bodies. For example, HKEX (Hong Kong Stock Exchange) which is Asia's third largest stock exchange has no clear definition of manipulation in the Corporations Act 2001 (Cth) (Dionigi et al., 2014). For its latent nature and vague definition across markets, it often gets difficult to empirically prove the existence of manipulation.

Stock market manipulation started getting scholarly attention from early 1990s (John \& Narayanan, 1997). It's a growing concern in the emerging Asian markets because they have securities that are very thinly traded and are vulnerable to manipulation. Developed markets are also not free from the insidious influence of manipulation. One of the most regulated markets in the world, ASX (Australia Stock Exchange) shows empirical evidence of the prevalence of manipulation, however, the number of instances that got caught by the regulatory bodies are scarce (Armson, 2009). For regulatory perspective, the difficulty is that it's hard to detect manipulation for its latent nature.

This paper tries to give a simple yet practical approach to measuring stock market manipulation using Structural Equation Modelling (SEM). The model can be used to measure the overall prevalence of manipulation across markets. With such comparison, it will be possible to create an index of stock market manipulation which will allow investors to take more informed decisions, especially to those who consider international diversification. The following section of the paper explains the model in detail.

\section{THE MODEL}

\subsection{Quantification of a hidden variable: a brief introduction to the well-being studies as a detour}

The focal point for setting up such a model is to ensure financial well-being of investors. An uninformed investor becoming a victim of stock market manipulation can fall into a situation of financial predicament. There have been documented cases of immense sufferings and even suicide among the victims of manipulative acts, predominantly in emerging markets (Mia, 2012). Therefore, this model bears close resemblance with the literature on economic well-being. We hence provide a brief outline of the models used to capture economic well-being as a guidepost for our work. It is imperative to understand that the basic foundation of our approach is close to the evolving literature on the measurement of human well-being. In the existing literature on financial markets, ours is the first attempt to quantify manipulation on the basis of a hidden, or latent, variable.

At the early stage of development, well-being was measured by taking a weighted average of different indicators that are closely related to well-being. There are numerous examples of well-being indices which are based on such measurement approach. Out of them, Physical Quality of Life Index (PQLI) (Morris, 1979) and Human Development Index (HDI) (UNDP, 1990) are two of the most well-known indices. Both these indices basically 
try to measure variables that are latent in nature and therefore quantify them observing other visible indicators such as infant mortality, adult literacy, per capita income, etc. Another well-known index that falls in this line would be the Human Poverty Index (Sen, 1997).

Such an approach of measuring a latent variable depends on two very crucial issues: (i) what indicators are chosen to indirectly measure the latent variable and (ii) the arbitrary weight given to each of those indicators. Over the recent years, other improved indices have been proposed that include extensive justification of the variables and indicators included in the model and also the weight distribution.

By studying the construction of these models, it can be concluded that (i) there is no direct method of measuring the underlying concept as it doesn't manifest itself in quantifiable form (i.e., latent) and (ii) it depicts its presence through multiple indicators as just one indicator is not a true measurement of the underlying concept as a whole. Such line of reasoning is dealt with statistical approaches such as SEM, factor analysis and multiple indicators and multiple causes (MIMIC). Psychology is a field of study which requires quantification of many latent variables, hence, use of latent variable models is quite common. Readers can find some great coverage on Bollen (1983), Knott and Bartholomew (1999), Skrondal and Rabe-Hesketh (2004) and Muthén (2002).

Out of all the prominent statistical approaches that deal with latent variables, the MIMIC model (Jöreskog \& Goldberger, 1975) has a very unique property in measuring the underlying concept (i.e., well-being). In its investigation approach, it not only believes that there are observable indicators of the latent concept, but also exogenous causal factors (observable) that influence the hidden variable. Now if we consider stock market manipulation in this context, we can see the resemblance as it is also latent in nature, however, portrays the presence through different observable indicators. Simultaneously there are myriad of causal factors that influence the occurrence of manipulation. Thus, MIMIC is a perfect fit as a model to our measurement approach of manipulation. More on this is explained in the following section.

\subsection{The prototype index of manipulation}

Our starting point is that the manipulation of a stock is captured by a host of indicators like the excess returns and variance of returns of a stock against the benchmark of the market portfolio. These measures are imperfect measures of manipulation. The problem is that all these measures are imperfect indicators of an unobserved variable called market manipulation. More importantly, manipulation is propelled by various unobserved latent causes/variables like economic, legal, regulatory and social conditions, cultural issues, psychological factors (various fears and mania), institutional weaknesses and business climate within a market. The critical point for us to realize is that these latent variables have differential impacts on different indicators of manipulation, so we will need the endogenous model to measure impacts of these latent variables on the indicators of manipulation. What is also extremely important is that a set of exogenous factors, which we term as observed variables in our model, impact on the latent variables, which thereby differentially impact on the indicators of manipulation.

By simultaneously modeling the observed variables, latent variables and indicators of peace in a single framework, we will be able to provide an appropriate mechanism to evaluate various indices of manipulation and from there carry out the "reverse-engineering" to tweak the observed variables to home on equilibrium levels of manipulation as expressed by different indicators of manipulation. The interactions between observed variables, latent variables and indicators of manipulation will be explained later.

\subsection{Methodology, data and variables}

Manipulation is often taken as a proxy for absence of frauds in financial markets and interpreted as a departure from the (market) equilibrium. Financial models came to be cast as general equilibrium models with presumed perfectly competitive product markets in which financial markets act as a conduit for the allocation of scarce resources across sectors. Thus, financial markets are 
a matching device between savers and investors. In the process of matching, information plays a critical role and substantial profits are made from the timings of purchases and sales of stocks. The manipulation is thus critically linked to the creation, arrival and dissemination of information or rumors/mis-information. Thus, the immediate impact of manipulation is on the time profile of returns, or excess returns, from an asset and the excess volatility of returns that can't be explained by the fundamentals. In our basic setup, we will use these two variables as the indicators of stock market manipulation.

\subsection{Manipulation as a latent variable: major contributions of our model}

We attempt to make two principal contributions: first, we model manipulation of a stock as an unobservable, or latent link, variable between observable causes and also observable indicators. This formulation will help to develop an index of manipulation by reducing the problem of bias, inconsistency, and arbitrary weights. Secondly, from the postulated model, we can estimate, compare, and analyze the manipulation indices for major stocks of countries. This will enable us to offer a ranking of stocks in terms of the index of manipulation for each country. We can then aggregate the indices for each country to generate an overall global index of manipulation.

We interpret the manipulation of a stock as a latent variable, $Q^{*}$, in the form of a multiple indicators and multiple causes (MIMIC) model. This approach exploits systematic relations between various indicators of manipulation and between manipulation and multiple causes. Therefore, to construct a model that can address manipulation, we need to first identify the causal factors and the indicators. This subsequently will also enable us to identify the determinants of manipulation and eventually come up with a global index of manipulation. Thus our proposed model resembles Jöreskog (1970) and Jöreskog and Goldberger (1975) models of multiple indicators and multiple causes.

In our proposed model, manipulation $\left(Q^{*}\right)$ is a function of a vector of causal variables, $X$, as $Q^{*}=f(X, u)$, where $u$ is a stochastic discrep- ancy. The next step is to specify a string of equations to define the observable indicators, $Y$, that are assumed to be determined by both $Q^{*}$ and other exogenous variables, $Z$, as $Y=g\left(Q^{*}, Z, v\right)$ where $v$ is a vector of stochastic discrepancies in the equations. The latent variable $Q^{*}$ which is manipulation in the current context can then be measured by observing $Y$ and $X$, and also observing other exogenous variables, $Z$. For each stock of a country, we can use a time series of $X$ and $Y$ from where we can calculate $Q^{*}$ for each stock. This can allow us to prepare a ranking of each stock within a country as an ordering in terms of the degree of manipulation. By aggregating the index for each nation, it will be possible to offer the ranking of each country in terms of the manipulation of their financial markets.

We then intend to generate a global index of manipulation that can aid investors greatly in taking informed decision and understanding the underlying risk of their investment decision by improving and progressing this elementary model in future endeavors.

\subsection{Methodology}

The MIMIC model postulates the latent variable manipulation $\left(Q^{*}\right)$ to be a function of the causal factors:

$$
Q^{*}=f\left(X_{1}, X_{2} \ldots X_{n}, \varepsilon\right)
$$

$X_{1}, X_{2} \ldots X_{n}$ are the causal factors of manipulation and $\varepsilon$ is the error term and $f($.$) is the func-$ tional relationship.

The MIMIC model also postulates that the vector of indicators of manipulation $(Y)$ is a function of the latent variable $Q^{*}$ :

$$
\begin{aligned}
& Y_{1}=G_{1}\left(Q^{*}, u_{1}\right), \\
& Y_{2}=G_{2}\left(Q^{*}, u_{2}\right), \\
& \ldots \\
& Y_{m}=G_{m}\left(Q^{*}, u_{m}\right),
\end{aligned}
$$




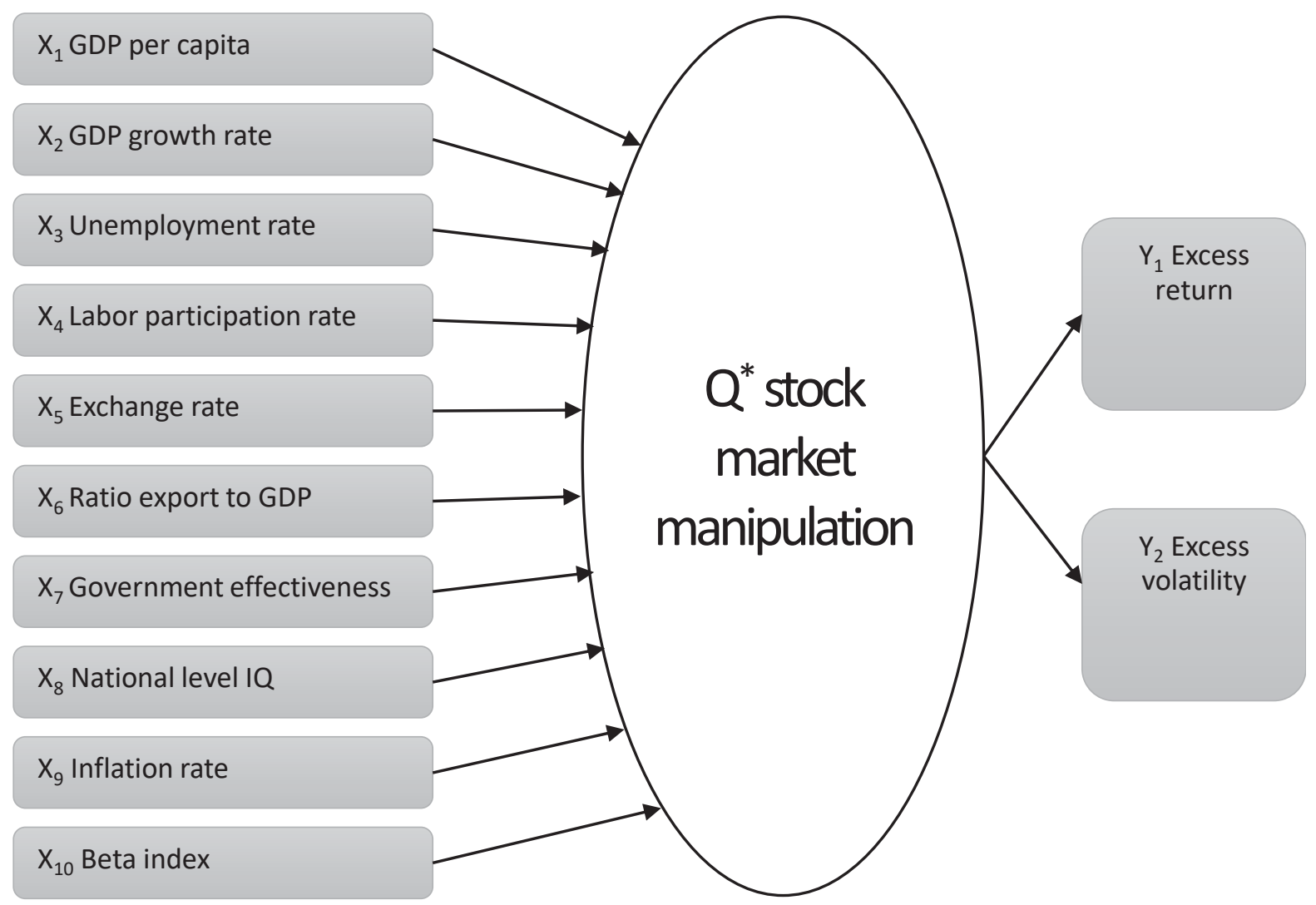

Figure 1. MIMIC 10-1-2

where $G_{1}(),. \ldots, G_{m}$ indicate the form of the relationships between indicators and the latent variable $Q^{*}$ and $u_{1}, \ldots, u_{m}$ are stochastic errors. The MIMIC model (1a)-(1b) represents a set of interdependent structural equations. In order to complete the specification of the model, one will need to specify the form of the interdependent structural equations (1a)-(1b), and one must also specify the form of the probability distribution of the errors $u_{1}, u_{2}, \ldots, u_{m}$ and $\varepsilon$. The linear specifications will lead to the following MIMIC model:

$$
Y=\beta \alpha^{\prime} X+(\beta \varepsilon+u),
$$

where

$$
\begin{aligned}
& Y=\beta Q^{*}+\varepsilon, \\
& Q^{*}=\alpha X+u .
\end{aligned}
$$

Note that (2a) and (2b) are the linearized version of (1a) and (1b) and $\beta$ is the vector of coefficients to measure the marginal impact of $Q^{*}$ on the manipulation indicators and $\alpha$ is the vector of coef- ficients that measure the marginal impacts of the "causes of manipulation" on the latent variable $\left(Q^{*}\right)$. A graphical demonstration of MIMIC (101-2) is given in Figure 1.

\subsection{Indicators and casual variables of manipulation}

The main intuition of the MIMIC approach is that some variables, or statistics, related to consistency are indicators of manipulation, while others signify effects or outputs of causal factors, or inputs, of manipulation. In other words, distinction can be made between causes of manipulation and indicators of manipulation. In the context of MIMIC model, QOL is captured by several imperfect indicators and explained by several economic and social causes. QOL is thus a multidimensional index composed of life expectancy at birth, infant mortality rate, and death rate. In our empirical analysis of manipulation, similar to the construction of QOL index, we consider two indicators of manipulation. The overall manipulation index is a linear combination of these two indicators. The 
overall index is determined by the interaction of various causal variables. In what follows, we briefly discuss the various dimensions/domains of the causal factors that will be used in the model.

The two major indicators of manipulation that we used in our model are excess return and excess volatility. In general, excess return is defined as any risk adjusted return that is above the return suggested by a pricing model, i.e., CAPM. A study of 40 incidences of stock market manipulation in Hong Kong Stock Exchange revealed the relationship between market manipulation and artificially generated excess return (Gerace et al., 2014). Excess return certainly can be caused by other non-manipulative reasons and is not always an indication of manipulation, however, is a major candidate for being one of the observable indicators in our model. Excess volatility, on the other hand, is fluctuation in the stock price that can't be explained with the available discount factors and can't be justified by fundamentals. Excessive market volatility is often considered as a sign of market manipulation, specially in emerging markets (Uppal \& Mangla, 2006). Hence, we have included these two imperfect but observable indicators of manipulation in our proposed model.

\section{Domain 1: Pure economic factors as determi- nants of manipulation}

We have considered the following two economic factors as causal variables for determining manipulation of a stock in a nation, which thereby impacts on its degree of stock market manipulation: GDP per capita and GDP growth. Both these factors have direct and indirect positive and negative effects on manipulation. On the one hand, increasing GDP per capita and GDP growth are expected to increase the opportunity cost of manipulation and thereby lowers manipulation. On the other hand, they can precipitate manipulation if the degree of rivalry between sectors increases.

\section{Domain 2: Labor market conditions}

We have included the following two factors to capture the state of the labor market, which can influence the overall profitability in an economy and thereby manipulation. They are the unemployment rate and the labor force participation rate.

\section{Domain 3: International factors}

The degree of international integration and the fluctuations in exchange rates can impact on profitability and thereby the incentives for market manipulation. In our work, we consider the exchange rates and the ratio of exports to GDP as causes of manipulation originating in the overseas sectors.

\section{Domain 4: Quality of governance factors}

One of the major deterrence to manipulation is the quality of governance that seeks to enforce the rule of law, which thereby makes manipulation unprofitable activities (Dixit, 2007). For characterizing the quality of governance in a nation, or region, one can consider the following indicators: inflation rates, EPI (environment performance index), national level of IQ, government effectiveness, control of corruption, percentage of central government debt - GDP ratio. In this work, we will consider inflation rates, national level IQ data and government effectiveness. Note that the national IQ data, as developed by Lynn and Vanhanen (2006), can be controversial since they suggest some kind of unproven link between human races and their collective intelligence (Ervik, 2003). However, from Richardson (2004) we know that the IQ indicators provide invaluable and unintentional information, not about races and intelligence, but about the presence and activism of educated middle class in a country. Since, the middle class plays a critical role in enforcing disciplines on a government through the political system, we will use the IQ data of Lynn and Vanhanen as a proxy for quality of governance.

\section{Domain 5: Systematic risk factors}

In this work, we also need to consider the business confidence as an important factor for determining the legal framework of a country. It is important to note that this is a common environment that each final stock of a country faces. Hence, there is not much point in taking the business confidence as a determining factor. Instead, we choose the beta index of a stock as a measure of underlying risk for each asset, which in turn determines the scope and costs of manipulation. 


\section{SCOPE OF THIS MODEL AND FURTHER RESEARCH IMPLICATIONS}

The model proposed here is at its very rudimentary state, however, it is a new line of reasoning and has the scope to build something much more profound based on this elementary idea. The possibility of coming up with a global manipulation index along the line signifies the wider scope this model has. Such an index will create significant value for the investors, therefore enhancing their financial wellbeing. Nevertheless, much more work is needed to shape this raw idea into something more practical and the work should start from identifying the causal factors and the indicating variables with a thorough review of the literature following this guideline provided by us. Once the model has been refined, some empirical analysis will enable future researchers to initiate the work of preparing country specific index and finally a global index of manipulation.

\section{CONCLUSION}

In the existing literature, there is a scanty attempt to measure market manipulation since it is difficult to capture and mostly hidden. Hence, the operationalization of an index of market manipulation calls forth measures. It is not an easy task to develop such index and this will be a preliminary attempt. The major problem for any approach to measure manipulation is that it can't be observed, hence an indirect and systematic approach is needed and this is what we tried to propose in this paper. A similar approach has been used by Dell'Anno (2003) where the author postulated a model to measure shadow economy in Italy which is latent by nature. The pathway from theory to practice is full of obstacles, especially when a latent variable is involved. We only have certain indicators of manipulation, which depend on various dimensions of manipulation. This simple observation will allow us to measure manipulation by means of several indicators and constructed as a composite index aggregating all these indicators and causal factors.

\section{REFERENCES}

1. Allen, F., \& Gale, D. (1992). Stock-price manipulation. The Review of Financial Studies, 5(3), 503-529.

2. Armson, E. (2009). False Trading and Market Rigging in Australia. Company and Securities Law Journal, 27(11), 411. Retrieved from http://hdl.handle. net/1885/31905

3. Bollen, K. A. (1989). Structural equations with latent variables', New York, NY: Wiley.

4. Chatterjea, A., Cherian, J. A., \& Jarrow, R. A. (1993). Market manipulation and corporate finance: A new perspective. Financial management, 200-209.

5. Dell'Anno, R. (2003). Estimating the shadow economy in Italy: A structural equation approach.
6. Dionigi, G., Charles, C., Christopher, W., \& Paul, M. (2014). Stock Market Manipulation on the Hong Kong Stock Exchange. Australasian Accounting, 8(4), 105-140. http:// dx.doi.org/10.14453/aabfj.v8i4.7

7. Dixit, A. K. (2007) Lawlessness and economics: alternative modes of governance. Princeton University Press.

8. Ervik, A. O. (2003). IQ and the Wealth of Nations. The Economic Journal, 113(488).

9. Gerace, D., Chew, C., Whittaker, C., \& Mazzola, P. (2014). Stock Market Manipulation on the Hong Kong Stock Exchange. Australasian Accounting Business \& Finance Journal, 8(4), 105.

10. Goldwasser, V. (1999). Regulating Manipulation in Securities
Markets: Historical Perspectives and Policy Rationales. Australian Journal of Legal History, 5, 149.

11. Jarrow, R. A. (1992). Market manipulation, bubbles, corners, and short squeezes. Journal of financial and Quantitative Analysis, 27(3), 311-336.

12. John, K., \& Narayanan, R. (1997). Market manipulation and the role of insider trading regulations. The Journal of Business, 70(2), 217-247.

13. Jöreskog, K. G. (1970). A general method for estimating a linear structural equation system. ETS Research Report Series, 1970(2).

14. Jöreskog, K. G., \& Goldberger, A. S. (1975). Estimation of a model with multiple indicators and multiple causes of a single latent variable. Journal of the American Statistical Association, 70(351a), 631-639. 
15. Knott, M., \& Bartholomew, D. J. (1999). Latent variable models and factor analysis. Edward Arnold.

16. Lynn, R., \& Vanhanen, T. (2006). IQ and global inequality. Washington Summit Publishers.

17. Mia, M. A. H. (2012). Origin of \& Solution to Global Financial Meltdown: An Islamic View. International Journal of Business and Management, 7(12), 114 http://dx.doi.org/10.5539/ijbm. v7n12p114

18. Morris, M. D. (1979). Measuring the condition of the worlds poor: the physical quality of life index.

19. Muthén, B. O. (2002). Beyond SEM: General latent variable modeling. Behaviormetrika, 29(1), 81-117. Retrieved from https:// www.statmodel.com/download/ muthen1.pdf

20. Pickholz, M. G., \& Pickholz, J. (2001). Manipulation. Journal of Financial Crime, 9(2), 117-133.

21. Richardson, K. (2004). IQ and the Wealth of Nations. Nature Publishing Group.

22. Sen, G. (1997). Empowerment as an approach to poverty. Background paper to the Human Development Report, 1997. Bangalore, India: Unpublished paper.

23. Skrondal, A., \& Rabe-Hesketh, S. (2004). Generalized latent variable modeling: Multilevel, longitudinal, and structural equation models. Crc Press.

24. UNDP (1990). Human Development Report 1990: Concept and Measurement of human development. New York: Oxford University Press.

25. Uppal, J. Y., \& Mangla, I. U. (2006). Market volatility, manipulation, and regulatory response: a comparative study of Bombay and Karachi stock markets. The Pakistan Development Review, 1071-1083. Retrieved from http://www.jstor. org/stable/41260669

26. Vila, J.-L. (1989). Simple games of market manipulation. Economics Letters, 29(1), 21-26. 